\title{
Shakespeare en las letras del Perú
}

pur

Estuardo Núice

Ni William Shakespeare, ni los dramaturgos del Siglo de Oro español, como Lope y Calderón, llegaron a ser universalmente conocidos hasta fines del siglo XVIII, —o sea algo más de 100 años después de muertos. Antes sólo tuvieron una difusión muy relativa. Las traducciones de Shakespeare a los idiomas modernos es tarea que se proponen los escritores románticos del XIX, como W. Schlegel en Alemania y Victor Hugo en Francia. Por contagio, los pueblos latinos empiezan sólo en el Ochocientos a conocer en versiones más o menos fieles, los dramas y comedias del dramaturgo inglés. Asi se explica la tardía acogida de Shakespeare entre los poetas románticos cle la segunda mitad del siglo $X \mid X$. Un venezolano, radicado en el Perú, Juan Vicente Camacho y el escritor y diplomático peruano tgnacio-Noboa, son los primeros en revelar en traducciones castelíanas fragmentos del autorrde Hamiet. Por 1860 algunas compañías extranjeras traen en sus repertorios las comedias y después los dramas de Shakespeare. Un poco más tarde han de surgir la edición de traducciones de obras integras.

\section{José Arnaldo Márquez, gran traductor de Shakespeare}

Le corresponde la primacía en esta tarea (de la versión de obras completas de Shakespeare) a José Arnaldo Márquez, romántico y limeño, multifacético y trashumante, quien por razón de varias estadas en la América del Norte, desempeñando cargos consum lares, había adquirido el conocimiento y dominio del idioma inglés.

Estando en Barcelona por 1880, obtuvo contrato de la Editorial Maucci para traducir, conjuntamente con Marcelino Menén- 
ciez y Pelayo, los dramas de Shakespeare. Al poco tiempo, en 1883. 1884 aparecen los 4 volúmenes de la Biblioteca cie Artes y Letras, elegantemente empastados, que contienen las obras traducidas. Dos tomos (el I y III) estuvieron a cargo de Menéndez y Pelayc, y los otros (el II y el IV) a cargo de Márquez. Este tradujo las siguientes piezas: Sueño de una noche de Verano, Medida por Medida y Cuento de Invierno (II) y Julio César, Como gusteis, Comedia de equivocaciones, Las alegres comadres de Wincisor (IV).

Las versiones de Márquez fueron consideradas en su momen. to un dechado de exactitud y justeza en contraste con la vaguedad e infidelidad de otros intentos españoles anteriores. La expresión era elegante y muy medida y discreta.

Años después, las versiones fueron elogiadas y calificadas de espléndidas por Rubén Dario y el propio Menénclez y Pelayo - compañero de empresa - las llamó "una de las más calificadas versiones" y ajustadas tanto al espíritu del autor inglés como el genio de nuestra lengua Es de presumir que Márquez prestó eficaz ayuda a Menéndez Pelayo eir la parte que le cupo, pues io superaba en el conocimiento de la lengua inglesa y que, a su vez, el poligrafo español -encargado de la supervigilancia total cle la edición- habría pulido el estilo de Márquez, algo propenso a los galicismos o a los giros de la retórica romántica. El contacto entre Márquez y Menéndez Pelayo debió ser estrecho durante las frecuentes visitas del segundo auBarcelohiaChechasspara este y otros menesteres intelectuales.

En el empeño de traductor, como en pocas cosas de su múltiple vida, Márquez se mostró discreto y justo, ponderado y sencillo, cuidadoso y fidedigno.

No obstante la buena acogida de las versiones de Márquez -elogiadas en su época por figuras insospechables y reeditadas últimamente en Buenos Aires- la crítica española más reciente ha silenciado inexplicablemente hasta la mera referencia del traductor peruano, con injusto olvido.

Luis Astrana Marín, traductor de las Obras completas de Shakespeare editadas por Aguilar, ha omitido el nombre de Márquez en el recuento de los traductores del dramaturgo en lengua española, no obstante mencionar a Menéndez y Pelayo. El afán de si- 
tuarse como el primer traductor de Shakespeare indujo a Astrana a desdeñar tan conspicuas versiones producidas por un hombre de inquietudes universales, a quien habría que proclamar el más calificado traductor de Shakespeare en el Perú y en Hispanoamérica.

\section{Shakespeare en criollo}

Nemesio Vargas, historiador y polígloto, estudioso y buscador de aspectos originales de las cosas, publicó a fines del XIX una traducción completa del Hamlet de Shakespeare (Lima, 1898), acaso la única edición erudita de la tragedia del Príncipe de Dinamarca hecha en América. (Completaba Vargas el empeño de Márquez, quien no comprendió dentro de sus versiones, la del Hamlet). Ricardo Palma, con cierta sorna, recomendaba esta traducción de Vargas a sus amigos, como "una delicia" y como "remedio eficaz contra el spleen". La razón de la ironía la examinaremos después. Veremos antes las virtudes de la obra.

Nemesio Vargas realizó en el empeño de traducir Hamlet, el primer intento de hacer en castellano una versión anotada, con gran aparato erudito. No desmereció el volumen de Vargas frente a otras ediciones universitarias europeas de Shakespeare. En la introducción cle la obra, demostró Vargas un conocimiento cabal de la obra de Shakespeare i una información al dia de los trabajos críticos de los mejores especialistas de Inglaterra, Alemania y Francia. Explicó cómo había trabajado su traducción ${ }^{-}$y expuso los problemas linguísticos de interpretación del texto antiguo, con gran lujo de citas de los críticos especializados. Superó sin duda las expectativas al realizar una traducción anotada y erudita, pues las versiones de Márquez habían sido meros traslados sin aparato bibliográfico ni crítico. Se permitía Vargas aseverar que "Shakespeare aún no ha sido traducido", con lo que dejaba de lado otros intentos incluso el de Márquez y Menéndez Pelayo, de quienes no quiso acordarse.

El carácter erudito de la obra de Vargas debe ser justipreciado en lo que significó en nuestro ambiente, con los escasos medios de que se disponía en aquella época. Ni antes ni después se ha emprendido en el Perú una semejante empresa en materia de traducción literaria. 
En cuanto al texto mismo, hay muchos pasajes acertudamente trasladados, con expresión cuidada y justa. Sin duda, Vargas - há. bil conocedor de lenguas muertas y vivas- conocia la lengua inglesa moderna y artigua. Pere el perfil grotesco de la versión surge cuando el traductor pretende trasponer la expresión particular y desenfrenada de personajes del pueblo. En la escena del cementerio los sepultureros alternan con Hamlet $y$ usan la interjección criollisima "jajailas!" o el tratamiento $y$ apelativo tan peruano: "Oye cholo", donde sćlo existe un "hear you" en el original.

El democrático lenguaje de los buenos y rústicos panteoneros ingleses adquiere grotesco contorno en esta peruanización de sus expresiones, contenidas en la versión que regocịaba a Palına y a nuestros abuelos.

En descargo de la intención de Vargas pero no cic su mal gusto, tal vez pudiera establecerse que el traductor pretendió subrayar el contraste entre la expresión señorial de reyes y cortesanos y la de gentes del pueblo. Otros traductores no se habian perca. tado de este contraste $y$ habían atribuido a los personajes populares igual tono de dignidad y estiramiento que el de los nobles. Vargas quiso enmendar esa inadvertencia pero se excedió en el in. tento con los resultados ya apuntados.

Hay otras caidas, como cuando la Reina se dirige a Polonio y lo insta a que hable concretamente (Morer'matter, with less art), lo cual traduce con un insólito neologismo: "menos cspuma y más ginger ale". En otro pasaje el propio Hamlet califica cle "guapos chicos" a dos cortesanos interlocutores, traduciendo así el "good lads" del original, o el mismo Hamlet pronuncia la interjección "Cascaritas!", poniéndose a tono con los sepultureros.

El anecdotario literario del Perú enriqueció su caudal con estas perlas, pero todo ello no opaca la esforzada tarea de un escritor peruano a quien la cultura del país debe uno de sus primeros estudios históricos nacionales $y$ otras conspicuas traducciones del inglés, del italiano y sobre todo del alemán, idioma del que virtió con gran dignidad las obras "Emilia Galotti" y "Laoconte" de G. $E$. Lessing. 
Ignacio Noboa, primer traductor fragmentario

$\mathrm{Si}$ es verciad que la primacia en la traducción de obras inlegras de Shakespeare le corresponde a José Arnaido Márquez, también es cierto que el primer traductor de fragmentos shakespirianos fue sin lugar a cluda, en el Perú, Pedro Ignacio Noboa, quien a la vez se perfiló un comentarista fervoroso del genio inglés desde las páginas de La Revisia de Lima, en agosto de 1860.

Nacido en Árequipa en 1811, Noboa inabía recibido una cuidada educación humanista en París. Alii llegó muy joven (a los 15 años) y permaneció casi un decenio. Alumno del Colegio de Francia, recibió sólida formación juridica y económica, escuchando lecciones del célebre Pinheiro Ferreira y del no menos famoso economista Juan Bautista Say. Pero en Noboa alentaba la vocación literaria que empieza a revelarse entre los años de 1830 a 35 , en la capital francesa, al conjuro del movimiento romántico que encabezaba Victor Hugo. Conoce alli también a José de Espronceda, entonces emigrado, y vive los días angustiosos de la Revolución de 1830 y el surgimiento de la querella entre clásicos y románticos. No se ha insistido lo suficiente en la figura de Noboa como uno de los propulsores de la nueva corriente romántica a su regreso al Perú, en 1835, en lo cual sería con Felipe Pardo, su contemporáneo, un precursor de la siguiente generación, la de Palma y su bohemia, que irrumpe en el medio peruano a partir cle 1850 . Desde antes de dicha fecha, Noboa J Jadicadol enil Arequipa, actúa, con el grupo romántico de dicha ciudad y publica sus primeros poemas en periódicos diversos, antes de ser consignados en La Lira Arequipeña. Discípulo de Andrés Martínez y vivanquista, resulta diputado en 1851-52, y en tal carácter se traslada a Lima, incorporándose al grupo romántico cle Palma, quien lo cita y lo dibuja entre los más maduros y "peinando canas" como Manuel del Carpio, Manuel Ferreyros y José María Seguín. Alternaba el culto de las letras, con actividades politicas y labores juridicas (en las que fue uno de los redactores del Código Penal de 1863).

Su dedicación a las letras es nutrida en dos publicaciones invalorables de la época: en El Constitucional (1858) y en La Revista de Lima (entre 1860 y 1861). En otras páginas examinamos la labor difusora, desde estas revistas, que emprendió Noboa de las 
letras francesos; en ello se períila como uno de los mas conspicuos criticos y traductores de Montaigne, Boulanger y Victor Hu. go, de quien resulta acaso el más nutrido comentarista y divulgador. Pero lo que ahora nos interesa es su contribucion al conocimiento de Shakespeare en el Perú.

El pensamiento liberal de Noboa se habia afirmado en la acción da las campañas de Benito Laso, Vigil, Mariategui, Jose Gregorio Paz Soldán y José Gálvez y como ei Kornanticismo se deiinia por entonces como "el liberalismo en la literatura", resultaba consecuente su inclinación a esa tenclencia y su afición por el "democratismo" que exalta en Snakespeare y cierta reacción contra el "aristocratismo" ( sic) del poeta ingiés Byron, que encandila a la generacion mas joven. Por lo demás, del ideario liberal participaba toda la nueva generación de poetas románticos que como Ricardo Paima, reaccionaban contra el vuelco conservador del Presidente Castilla en 1800, no obstante que en 1854 habia sido el caudillo de la revolución liberal. Noboa concidió con ellos y luchó en los periódicos mencionacios. Un breve gobierno liberal lo llevó más tarde al Ministerio de Hacienda que desempeño entre 1863 y 1864, para volver luego a la oposición hasta su nombramiento de diplomático en Chile (1869-1874), falleciendo al año siguiente en Valparaiso.

Casi 40 años antes que Nemesio Vargas, Noboa habia escogido para traducir de Hantefla mismaéscena de los sepultureros en el cementeriojque dio tanto que Gomentar en la versión del primero. El criterio democrático con que miraba la producción de Shakespeare, induce a Noboa a seleccionar el fragmento para su traslado y para su comentario. Perseguía mantener la fidelidad del original pero atribuye a los sepultureros un lenguaj: elevado y hasta erudito, tanto o más que en el original y hasta acentúa el tono juridico con que se expresa el primer sepulturero. En el fondo no practica ningún "democratismo" en su versión y lejos de eso los personajes populares resultan hablando un lenguaje impropio de su condición modesta.

Noboa comenta que el teatro de Shakespeare

"es un inmenso grito de la Edad Media contra las desigualdades sociales... El autor interrumpe el drama de la corte para 
hacernos asistir a esta bella escena democrática en que dos sepultureros... cavan el sepulcro de Ofelia y hablan entre ellos y poco después vendrá a mezclarse en la conversación Hamlet".

Y asi en la escena traducida por Noboa, el primer sepulturero se expresa de esta suerte:

Sepulturero 1:-Es evidente que ella ha muerto se offendendo: ni puede scr c.z o:ro modo; el punto de derecho es el siguiente: si yo me ahogo deliberadamente, esto denota un acto, y un acto tielle ces licimpos: el gesto, la acción y la ejecución: luego, clla se ha ánogacio porque lo ha querido.

El lenguaje empleado es impropio. El sepulturero habla con la versación de un jurista y la exactitud de un hombre culto, connotaciones de que carece el original, no obstante el latinajo. Esa caícia del traductor Noboa quiso posteriormente corregirla Vargas, acercándose a la fidelidad con el recurso de hacer hablar al sepulturero "en vulgar", a fin de que diera la exacta impresión de su carácter popular. La intención era acertada en Vargas, pero su realización carece de la sutileza necesaria al no difereıciar entre lenguaje vulgar y lenguaje acriollado, con los resultados que sancionó el sarcasmo o la maliciosa sorna de los lectores peruanos de su época.

Todo hace pensar que Noboa no traducía precisamente del original sino de la versión francesa de Víctor Hugo. Lo delatan en el comentario al texto $y$ en éste mismo, la frecuencia del vocabulario y la construcción galicista, que lo condujo a desnaturalizar el texto traducido. En cambio, es indudable la cercanía al original de la versión de Vargas y su acierto de pretender volcar la expresividad popular de los personajes modestos, aunque exagerando esos medios expresivos, sin contener en su justo límite su expansión temperamental. Este contraste ilustra los excesos del traductor literal y del traductor libre. El uno por ser demasiado fiel, deslustra el sentido y expresión del original. El otro, en su afán de lograr la versión más expresiva desnaturaliza el significado y logra sólo un efecto distinto e inesperado. Ambos traicionaron al autor, confirmando el antiguo apotegma: traduttore, traditore. Doble traición: en Noboa, por defecto; en Vargas por exceso. 


\section{Glosadores, exégetas e intérpretes de Shakespeare}

Al lado de los traductores, destaca en el Ferú una amplia gama de glosadores y exégetas de Shakespeare a partir de la segunda mitad del siglo $X I X$. Por esa época decia Ricardo Palma:

"Traduciamos (los poetas románticos de la bohemia) con infinito trabajo a Shakespeare y Byron..."

En El Heraldo de Lima aparecieron por 1854, algunas versiones aisladas de Shakespeare y en La Revista de Lima, por 1960 (tomo 11, pp. 153-156 y 290-297), Ignacio Nobon, diplomático y poeta arequipeño del romanticismo, publicó el primer artículo crítico sobre el autor de Hamlet, que precedia a la versión de una escena del acto $V$ del mismo drama, que incluyó el célebre monólogo, y preguntaba Noboa a sus lectores:

¿Quién se ha ocupado nunca de el entre nosotros?

¿Quién se ha molestado en irazar unas lineas dando a conocer la grandeza de sus concepciones? "Creo que nadie".

En efecto no hay rastro anterior a 1860 de exégesis o comentario de Shakespeare en el Perú.

Pero el mismo Noboa daba a conocer que alguna compañía de artistas españoles habia representado años antes el Hamlet, seguramente alguno "dertos Ponvenciohalesn"arfeglos" que se hicieron en la península descle fines del siglo anterior.

La critica de Noboa era favorable a la mejor apreciación de Shakespeare, como dramaturgo social, en oposición al aristocraticismo un tanto individualista de Byron, que habia logrado notable difusión descle muchos años antes, influyendo decididamente a la nueva generación peruana de escritores. $Y$ decia más:

"Vió pues, (Shakespeare) la sociedad por abajo, como Byron la vió por arriba... Tanto como Byron ignoraba y descleñaba a la multitud (ha dicho $V$. Hugo) otro tanto Shakespeare la conocía y la amaba... por eso es que Byron aristócrata, ha dejado una obra de misantropía y de negación, al paso que Shakespeare hombre del pueblo, ha hecho una obra de afirmación y de humanidad". 
La generación que sigue a Ncboa parece conocer más intimamente a Shakespeare y resulta más identificada con su genio creador. No se comenta ni se traduce al genio, se le glosa y se le incorpora en los versos de esos pottas peruanos. Federico Flores Galindo le dedica una versada cle 30 tercetos, publicada en El Correo del Perú en 1876, ( $N:$ XLIV), de los cuales bastan como muestra los siguientes:

De tus obras no sé cuál más admiro

Si todas a la vez pasman mi mente cual de los astros el eterno giro

Cada tragedia tuya es un ejemplo de crímenes, de amor y da liaroismo, ¿Sacras columnas de apolíneo templo!

y menciona a continuación el Ricardo III, el Hamlet, Las alegres comadres de Windsor, dando razón de sus lecturas fervorosas.

Otro poeta de la época, el tacneño Modesto Molina, en la misma publicación, ( $N$ : XLIII), declica a "Hamlet" unos cuartetos endecasilabos, que concluyen asi:

Ante ese hombre que muere a cada instante

juguete de la duda y de la suerte, me he dicho con el llanto en el semblante,

Señor... dormir. .. ¿asi serà la muerte?

Más calidad poética luce esta octava de Aurora Amor dedicada a Shakespeare, por Luis Benjamin Cisneros en 1885:

El pertinaz, desesperado grito

que lanzabalę la focanprometeonvel'SO»

preguntando a lo eterno e infinito

el "porqué" de la vida y el deseo,

es el mismo de Hamlet el maldito

lúgubre loco, ante el inerte y feo

cráneo en que pace roedor gusano,

santuario ayer del pansamiento humano.

Las representaciones de Macbeth y El Niercader de Venecia, se han hecho más frecuentes, según registró El Comercio de Lima ( 6 y 11 de setiembre de 1865, 9 de junio de 1888, 4 de febrero de 1896, etc.).

Los comentarios periodísticos - v.g. el estudio de Hamlet por Scipion Llona, 1888- alternan con las monografias universitarias, como las tesis de Constantino Salazar (1890) y sobre todo la de Luis Miró Quesada (1903). 
A fines de siglo. ia figura de Hamlet mantiene la obsesiva atención de los modernistas. Joso Sumos Chocano le dedica dos poe. mas de su Itbro La Selva Virgen (Lima, 1396) y al poco tiempo el drame El nuevo Himlet, estrenado en 1898 y publicado al año si. guiente. El personaie principa! es un ser atormentado por el problema psicológico de Hamlet de lo cual da idea esta cuarteta:

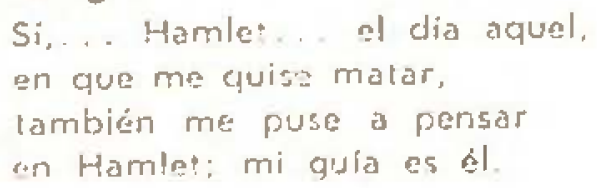

\section{El siglo $x \times$}

Contrastancio con Manued A. San Juan que a fines del XIX, $\rightrightarrows$ ! exaltar la figura de Voliaire, deprimia y descleñaba a Shakespeare, Enrique Bustamante y Babivián, poeta postmodernista, hace gala de su culto hamletiano:

\section{Ser o no ser; Dacsion, el pensamiento \\ nada importa.Perdidas, \\ como las olas, pasarán las vichas? \\ la vida es un momento. \\ $y$ es eterna la Muerte. \\ entre el ser yol ho ser. \\ la razón del nocser es la más fuerte.}

Poco después, en 1915, otro poeta de esa misma generacion aunque de otraf falidad Felipe Jsessone estrenaba en Madrid, su tragicomedia en 4 actos, El interprete de Hamlet. En un drama.

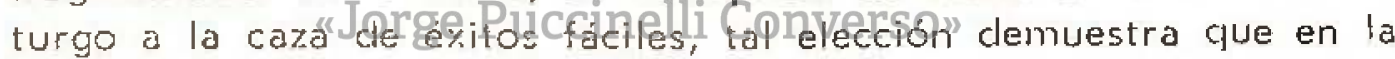
época de su estreno, el interés por Hamlet era latente, tanto an los medios hispanoamericanos como en el medio español.

Se han agregado por ese tiempo otros traductores selectos de fragmentos como Germán Leguía y Martínez y Manuel Beltroy.

En años más recientes, Shakespeare ha pasado al acervo popular, gracias a las ediciones populares (como la de La Prensa, en 1917 ), a los comentarios de divulgación (como los de A. Valdelomar, Rodolfo Ledgarci, Aurelio Miró Quesada, Emilio Armaza, etc.), a las investigaciones de psicología aplicada a los personajes, a los estudios universitarios, a su incorporación en los programas literarios cle secundaria, a su difusión en excelentes transposiciones cinematográficas y a la presentación teatral a cargo de profesionales $y$ aficionados de calidad, con un nuevo sentido de la escena. 